\title{
Genetic signatures in an invasive parasite of Anguilla anguilla correlate with differential stock management
}

\author{
S. Wielgoss*††, F. Hollandt*, T. Wirth $§$ and A. Meyer*\| \\ *Lehrstuhl für Zoologie und Evolutionsbiologie, Fachbereich Biologie, Universität Konstanz, \\ Universitätsstrasse 10, 78457 Konstanz, Germany, †Laboratoire Adaptation et Pathogénie des \\ Micro-organismes, Université Joseph Fourier Grenoble I, Institut Jean Roget, Campus Santé, \\ Domaine de la Merci, BP 170, 38042 Grenoble cedex 9, France, \$CNRS UMR 5163, Institut \\ Jean Roget, Campus Santé, Domaine de la Merci, BP 170, 38042 Grenoble, France and \\ $\S E c o l e$ Pratique des Hautes Etudes, Département Systématique et Evolution, UMR-CNRS \\ 7205, Muséum National d'Histoire Naturelle, 16 Rue Buffon, 75005 Paris, France
}

\begin{abstract}
In this article, it is shown that available genetic tools for the omnipresent parasite Anguillicoloides crassus in European eels Anguilla anguilla are sensitive to different immigration rates into local A. anguilla stocks for two separated river systems. Relying on four highly polymorphic microsatellite markers, it was inferred that under natural recruitment, nematode samples meet Hardy-Weinberg expectations for a single panmictic population, while genetic signals show signs for a strong Wahlund effect most likely due to very recent population mixing under frequent restocking of young $A$. anguilla. This was indicated by a low but significant $F_{\mathrm{ST}}$ value among within-host populations (infrapopulations) along with high inbreeding indices $F_{\mathrm{IS}}$ consistent over all loci. The latter signal is shown to stem from high levels of admixture and the presence of first-generation migrants, and alternative explanations such as marker- and sex-specific biases in the nematode populations could be dismissed. Moreover, the slightly increased degree of relatedness within infrapopulations in the stocked river system cannot explain the excessive inbreeding values found and are most likely a direct consequence of recent influx of already infected fish harbouring parasites with different genetic signatures. Applying a simulation approach using known variables from the nematode's invasion history, only the artificial introduction of a Wahlund effect leads to a close match between simulated and real data, which is a strong argument for using the parasite as a biological tag for detecting and characterizing fish translocation.
\end{abstract}

Key words: A. crassus; biological tag; European eel; fish stocking; parasite; Wahlund effect.

\section{INTRODUCTION}

The peculiar life cycle of the European eel Anguilla anguilla (L.) comprises a continental resident stage and a long-distance migration loop (Tsukamoto et al., 2002) covering up to $6000 \mathrm{~km}$ in the open ocean to reach its spawning grounds in the Sargasso Sea. Since the early 1980 s, recruitment levels of $A$. anguilla glass eels have collapsed by 90-99\% (Moriarty, 1986, 1996; Dekker, 2000, 2003). This dramatic

$\|$ Author to whom correspondence should be addressed. Tel; +497531883069 ; fax; +497531883018 ; email: axel.meyer@uni-konstanz.de 
trend was actually preceded by a lack of spawners as depicted by reduced fishing harvest (ICES, 1976; Dekker, 2003), and the reduction in spawner escapement is thought to have led to an ongoing decline of the recruitment numbers representing a downward spiral (Dekker, 2009). Consequently, the European Commission has recently proposed a Council Regulation to establish quantitative management actions for protection and restoration of the A. anguilla stocks (COM, 2007). The Regulation mainly aims at increasing the proportion of $A$. anguilla silver eel biomass escaping to sea for a set of 'eel river basins', to be defined by each of the member states, the goal of which is dependent on a range of different quantitative criteria, including an overall reduction of harvest, reservation of a fraction of caught small fish $(<12 \mathrm{~cm})$ for restocking and reduction of mortality of migrating A. anguilla.

According to the multitude of causes proposed for the decline (Feunteun, 2002; Dekker, 2008), different measures must be taken to aid the recovery of $A$. anguilla, which are dependent on the 'eel river basin's' characteristics. For example, concentrated habitat restoration in the most important areas for glass eel recruitment of $A$. anguilla in south-western Europe (Atlantic parts of France, Spain and Portugal) should have the most significance for the global stock (Dekker, 2009). In addition, restocking with small $A$. anguilla was shown to have an overall positive effect on yield in the Baltic Sea regions (Wickström, 2001). Translocation of recruits (stocking), however, represents a considerable increase in distances to the spawning grounds and apparently constrains $A$. anguilla escapement in the Baltic Sea area (Westin, 1990, 2003).

In order to assess the impact of restocking more systematically, fish movement could be monitored by applying external artificial tags, e.g. Carlin tags (Westin, 1990) or miniaturized pop-up satellite archival tags (PSAT tags) (Aarestrup et al., 2009). This does not allow for routinely tracking $A$. anguilla on a global scale. On the other hand, first results using immersion marking with the chemical compounds oxytetracycline and azilarin red for $A$. anguilla glass eels before restocking appear promising as mass marking is feasible and growth and mortality of tagged $A$. anguilla are not affected (Simon et al., 2009).

In contrast to artificial tags, genetic markers are ubiquitously available. Due to the very low population genetic structure of $A$. anguilla across the whole distribution range (Lintas et al., 1998; Wirth \& Bernatchez, 2001, 2003; Maes \& Volckaert, 2002; Dannewitz et al., 2005), the parasite fauna is an attractive surrogate for monitoring A. anguilla transfer and migration behaviour. The movement and connectivity of stocks of lowly structured marine and migratory fishes by means of their parasite communities has a long and successful tradition (Herrington et al., 1939; Mosquera et al., 2000; MacKenzie, 2002). Recently, Criscione et al. (2006) demonstrated that the genetic assignment of steelhead trout Oncorhynchus mykiss (Walbaum) back to their river of origin is more powerful if the genetics of its freshwater-dependent trematode parasite are used instead of the host's own genetic information. While the application of genetic tools to trace movement of animals by means of their related parasites and pathogens has been proposed repeatedly (Wirth et al., 2005; Nieberding \& Olivieri, 2007), this feature remains largely underutilized for aquatic organisms.

One candidate for tracking the A. anguilla translocation is the omnipresent rhabditid nematode Anguillicoloides crassus (Moravec, 2006). Sampling and classification of nematodes is easy, average prevalence (per cent of hosts infected; Bush et al., 1997) reaches $>50 \%$ with around five nematodes per infected fish 
(Wielgoss et al., 2008), and the distribution range of $A$. crassus almost matches that of its host (Kirk, 2003), except for Iceland (Kristmundsson \& Helgason, 2007). Most importantly, the molecular genetic tools have already been developed (Wielgoss et al., 2007) and applied to survey the nematode's population genetic structure in different regions (Sasal et al., 2008; Wielgoss et al., 2008). The nematode's biology is extensively reviewed by Kirk (2003) and a description of its life cycle is depicted in Fig. 1.

Here, in a pilot study, the sensitivity of four microsatellite markers to frequent stocking of young A. anguilla in one river system in central Europe (Rhine) was assessed and contrasted to the genetic and morphometric signatures to a system with natural recruitment close to the sea in Brittany (Frémur). First, paying special attention to parasite structure into infrapopulations, as well as sex bias and marker defects, Hardy-Weinberg expectations (HWE), population differentiation and the degree of infrapopulation-level relatedness were studied. Second, genotype data from previously described locations across Europe are used as baseline (Wielgoss et al., 2008) to assess the role of admixture and the presence of first-generation migrants in explaining this pattern.

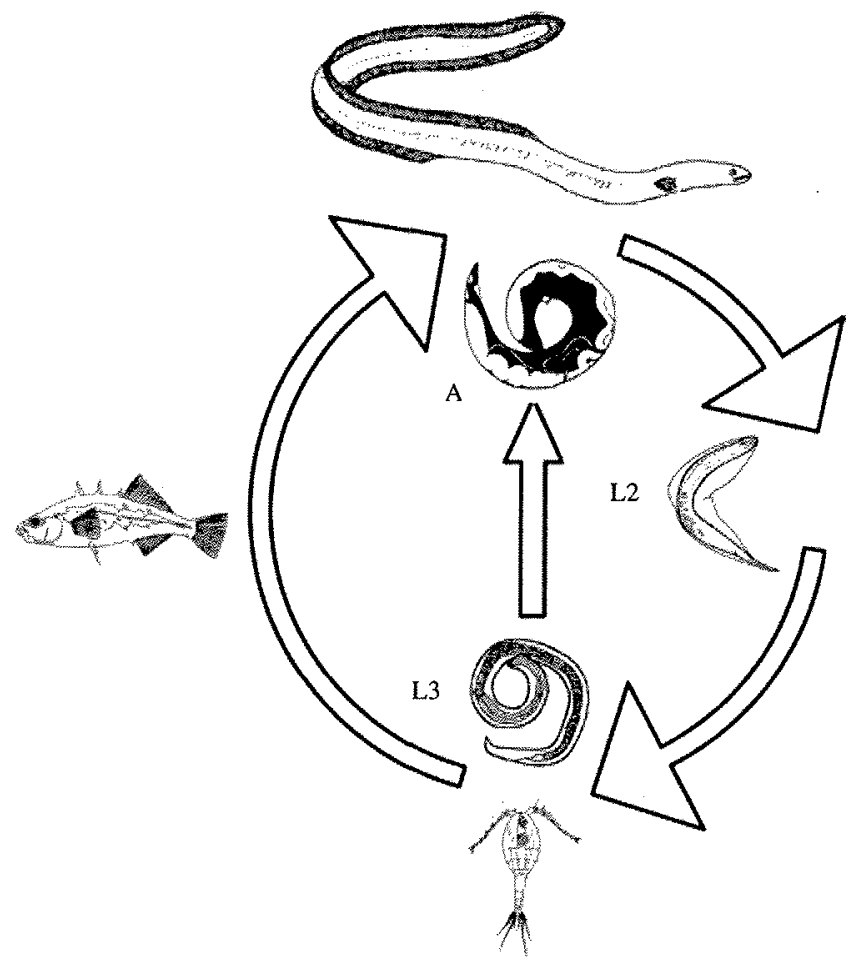

FiG. 1. Schematic life cycle of the invasive nematode parasite Anguillicoloides crassus. The adult nematodes (A) reproduce sexually in the swimbladder lumen of their final fish host, Anguilla anguilla. L2 larvae are extruded to the aqueous environment over the ductus pneumaticus and the intestine. Copepods and other small crustaceans serve as intermediate hosts (not species specific). Anguilla anguilla can get infected by ingesting $L 3$ larvae residing in both crustaceans (obligatory) and prey fishes (facultative). Since the immune defence mechanisms mounted against $A$. crassus are inefficient, most European wild $A$. anguilla harbour several adult nematodes in their swimbladder (Kirk, 2003; Wielgoss et al., 2008). 


\section{MATERIALS AND METHODS}

\section{SAMPLING MATERIAL}

All samples were collected with fyke nets in October 2006. The first sample derived from a small side arm along the River Rhine in Karlsruhe, Germany, called Rußheimer Altrhein (RHI; $49.212^{\circ} \mathrm{N} ; 8.398^{\circ} \mathrm{E}$ ). A total of $n=62$ A. anguilla were collected with a nematode prevalence of 0.32, and an infection intensity (Bush et al., 1997) of 5.6 adult nematodes per infected fish. The second locality was sampled in France upstream a dam system called Bois Joli in the River Frémur (FRE; $48.56^{\circ} \mathrm{N} ; 2.08^{\circ} \mathrm{W}$ ). A total of $n=70$ A. anguilla were sampled, with a nematode prevalence of 0.57 , and an infection intensity of 6.3 adult nematodes per infected fish. While the Rußheimer Altrhein is strongly influenced by annual restocking with 1000-2000 bootlace $A$. anguilla of total body length, $L_{\mathrm{T}}=10-15 \mathrm{~cm}$ ordered from various unspecified sources (mainly traders in northern Germany; F. Hartmann, pers. comm.), A. anguilla recruit naturally in the Bois Joli, which is situated only $6 \mathrm{~km}$ upstream of the sea, connected by the River Fremur. This river system is equipped with fish ladders and lifts, which are frequently surveyed by the company FISHPASS in Rennes, France. Captured A. anguilla were gutted and viscera removed and processed in the laboratory. All adult nematode parasites were assigned a label indicating their respective host infrapopulation (e.g. RHI21a, RHI21b, for two individual parasites sampled in the same host) and singly stored in screw-cap tubes in $70 \%$ ethanol until further investigation. For both localities, the largest within-host infrapopulations of the parasites (Bush et al, 1997) were investigated with $n=8$ (RHI) and $n=7$ (FRE). These harboured a total of $n=76$ (RHI) and $n=112$ (FRE) adult nematodes, respectively.

\section{MORPHOMETRICS AND SEXING}

Each nematode was classified and sexed according to Moravec \& Taraschewski (1988), photographed and total wet body mass $\left(M_{\mathrm{T}}\right)$ was determined to the first decimal of the mg-scale on a calibrated fine balance. Total length $\left(L_{T}\right)$ was approximated from the photographs using the $C A D$-programme $A B$ Viewer version 6.3 (Softgold Ltd; www.cadsofttools. com). The same mm-grid placed below each nematode specimen facilitated the conversion of pixel measures to the metric mm-scale (up to the first decimal). Since measurements along the nematodes' central lines were highly concordant with the measurements of the respective nematodes' circumferences $\left(n=62 ; r^{2}=0.997\right)$, the former measurement was used for all nematodes. Male nematodes below the balance's scale $(<0.1 \mathrm{mg})$ were excluded from the morphometric analyses, as were some female specimens due to body rupture (RHI: two females, six males; FRE: eight females, one male). Data were inspected for normal distribution (Shapiro-Wilks tests) and homoskedasticity (Breusch-Pagan tests) using $\mathrm{R}$ version 2.10.1 (www.r-project.org). Where necessary, data were normalized using transformation techniques as stated in the text. The nematodes nested within hosts, which in turn have been sampled randomly at two sites a priori chosen due to differences in stocking management (fixed). The following two linear mixed models were formulated for the tests:

$$
\begin{aligned}
Y_{i j k l} & =\mu+\alpha_{i}+B_{i j}+\gamma_{i j k}+\varepsilon_{i j k l} \\
Y_{i j l} & =\mu+\alpha_{i}+B_{i j}+\varepsilon_{i j l}
\end{aligned}
$$

where $Y_{i j(k) l}=$ response variable, $\mu=$ overall mean, $\alpha_{i}=i$ th location (fixed), $B_{i j}=j$ th infrapopulation in $i$ th location (random), $\gamma_{i j k}=k$ th sex in $j$ th infrapopulation in $i$ th location (fixed) and $\varepsilon_{i j(k) l}=$ random residual error.

Nested analyses of variance (nANOVA) were performed using the aov-function in $\mathrm{R}$ version 2.10.1. Alternatively, $F$-values and probabilities were calculated for fixed factors, given 'Infrapopulation' is random using the REML technique under the Ime-function, as supplied in the nlme-package. Moreover, to account for unequal sampling sizes among A. anguilla infrapopulations, the Satterthwaite approximation (Gaylor \& Hopper, 1969) was calculated by hand as outlined in Sokal \& Rohlf (1995) and $P$ values compared with the uncorrected calculations. In a first analysis, a three-level nANOVA (equation 1) was performed for both 
$L_{\mathrm{T}}$ and $M_{\mathrm{T}}$ following the procedure presented in Sokal \& Rohlf (1995). The hierarchy consisted of single nematodes of different sexes nested within hosts, host infrapopulations and local populations. In a second test, two-level nANOVAs (equation 2) were carried out focusing on both sexes separately to check for gender-specific variation. To simplify the models, interaction terms were removed, as neither was significant at the $5 \%$ level.

\section{MOLECULAR ANALYSES}

Genomic DNA was extracted using the high salt precipitation technique for animal tissues devised by Bruford et al. (1992). Individuals were screened at four microsatellite markers: AcrCT27, AcrCT53, AcrCT54 and AcrCA102, following a multiplex polymerase chain reaction (PCR) approach (Wielgoss et al., 2007). The PCR products were diluted 1:20 in fully deionized water, and $1.2 \mu \mathrm{l}$ of the bulk dilution was added to a sequencing plate containing $10.8 \mu \mathrm{l}$ of HiDi Formamide and $0.2 \mu \mathrm{l}$ of internal size standard. Due to an upgrade of sequencer hardware and chemistry during the project from ABl's 3100 to a $3130 x l$ genetic analyser, a total of 32 previously scored individuals were rerun on the new system to account for consistent size calling in GeneMapper.

\section{POPULATION-BASED MICROSATELLITE ANALYSES}

Microsatellite loci were tested for linkage disequilibrium and Hardy-Weinberg equilibrium (HWE) using Fisher's exact test in Genepop on the Web (Raymond \& Rousset, 1995). The markers were specifically tested for the presence of marker defects using the programme Microchecker (van Oosterhout et al., 2004). The observed and expected heterozygosities, and sex-specific $F$-statistics, as well as the jackknifing statistics were assessed using Génétix version 4.05 (Dawson \& Belkhir, 2001), and allelic richness after correcting for unequal sample sizes (rarefaction) were inferred using Hp-Rare (Kalinowski, 2005). An analysis of molecular variance (AMOVA) was performed to compare the distribution of the overall genetic variance among locations, infrapopulations and individuals (Excoffier et al., 1992) in Arlequin version 3.1 (Excoffier et al., 2005). Finally, pair-wise relatedness $r_{\mathrm{xy}}$ (Queller \& Goodnight, 1989) was calculated at the level of infrapopulations using SPAGeDi version 1.2g (Hardy \& Vekemans, 2002). For this purpose, $r_{\mathrm{xy}}$ measurements were exclusively calculated for infrapopulations within sampling localities. The observed total infrapopulation averages were compared with normally distributed samples of randomly reassigned values among hosts within locations (1000 draws). A right-tailed test for significance at the 5\% level was performed to test for significant departure from the null hypothesis of 'no difference in average relatedness among infrapopulations'. Finally, the presence of a Wahlund effect was simulated by generating data in Easypop version 1.7 (Balloux, 2001). Based on the inferred recent invasion history of A. crassus (Wielgoss et al., 2008), the simulation started from a single introduced population of effective size $N_{e}=1000$, split into 10 populations of size 100 and run for 100 generations and for four independent loci. It was assumed that genetic diversity was maximal with 50 alleles per locus and migration rates were kept at one instance per population and generation ( $m<0.01$; island model). After 100 generations, $F$-statistics were inferred for both separate and lumped data sets of size 1000 using Fstat version 2.9 .3 (Goudet, 1995).

\section{INDIVIDUAL-BASED MICROSATELLITE ANALYSES}

Two different Bayesian clustering techniques of individuals were utilized to estimate population genetic structure and degree of admixture without using a priori information on individual sampling locations. First, a factorial component analysis (FCA) implemented in Génétix version 4.05 (Dawson \& Belkhir, 2001) extracted a set of orthogonal axes of variation ranked by informativeness. The two-dimensional scatter plot based on the output matrix of eigenvalues was redrawn in Matlab version 7.8 (Release R2009a; The MathWorks Inc.; www.mathworks.com) for improved graphical representation. Second, genetic admixture in either population was assessed in Structure version 2.2 (Pritchard et al., 2000; Falush $e t$ al., $2003,2007)$. The data set was complemented by previously genotyped samples from southern France ( $n=41$; Camargue). Given the Rhine's genetic affinity towards north-eastern European populations and Frémur's derived 'Brittany' signature, the known number of European 
populations in the data set, $K=3$ (Wielgoss et al., 2008), was highly supported from sampling 200000 Markov chain Monte Carlo (MCMC) repeats after discarding the first 50000 steps (burn-ins). These analyses were performed under the admixture model, without prior information on sampling localities, and choosing correlated allele frequencies among populations. Hence, these settings were used to infer average individual population membership coefficients $(Q)$ and $\mathrm{CI}(P>0.05)$ assuming $K=3$ populations. To identify first-generation migrants in the data set, Rannala \& Mountain's (1997) Bayesian method was used as implemented in Geneclass version 2.0h (Piry et al., 2004). In brief, the programme derived the likelihood statistics $L_{\text {home }}$ and $\Lambda=\left(L_{\text {home }}-L_{\max }\right)$ (Paetkau et al., 2004) for individuals of either sampling site to be first-generation immigrants from a known baseline data set comprising 362 individuals derived from 11 broadly distributed European localities (Wielgoss et al., 2008). Subsequently, the probabilities for being a resident were derived for 10000 simulated individuals. The cut-off criterion was set to $P=0.05$. Individuals below this value were listed as potential immigrants from the proposed region.

\section{RESULTS}

\section{MORPHOMETRIC DIFFERENTIATION: REGIONS AND SEXES}

Sex ratios $\left(R_{\mathrm{S}}\right)$ are slightly skewed towards females in both sampling locations, with $R_{\mathrm{SRHI}}=1.23$ and $R_{\mathrm{SFRE}}=1 \cdot 38$. Heteroskedasticity could be refuted in all cases using Breusch-Pagan tests considering the linear models, equations (1) and (2) $(P>$ 0.05 , each), however, except for female $L_{\mathrm{T}}(P>0.05)$, neither measurement was normally distributed according to a Shapiro-Wilks test for normality $(P<0.01$, each). Since total data sets for $M_{\mathrm{T}}$ and $L_{\mathrm{T}}$ (Table I) including both sexes could

TABLE I. Sample sizes $(n)$, total masses $\left(M_{\mathrm{T}}\right)$ and total length $\left(L_{\mathrm{T}}\right)$ of adult parasitic nematodes, Anguillicoloides crassus, listed separately for sampling locality, infrapopulation and sex

\begin{tabular}{|c|c|c|c|c|c|c|}
\hline \multirow[b]{2}{*}{ Infrapopulation } & \multicolumn{3}{|c|}{ Females } & \multicolumn{3}{|c|}{ Males } \\
\hline & $n$ & $M_{\mathrm{T}}(\mathrm{mg})$ & $L_{\mathrm{T}}(\mathrm{mm})$ & $n$ & $M_{\mathrm{T}}(\mathrm{mg})$ & $L_{\mathrm{T}}(\mathrm{mm})$ \\
\hline \multicolumn{7}{|c|}{ River Rhine (RHI) } \\
\hline RHI04 & 2 & 82.4 & $25 \cdot 7$ & 3 & $8 \cdot 17$ & $16 \cdot 3$ \\
\hline RHI06 & 4 & $38 \cdot 1$ & $24 \cdot 3$ & 2 & 3.75 & $13 \cdot 3$ \\
\hline RHI11 & 5 & 72.7 & $27 \cdot 3$ & 3 & $25 \cdot 10$ & 32.7 \\
\hline RHI12 & 3 & $44 \cdot 0$ & $24 \cdot 1$ & 3 & $18 \cdot 30$ & $20 \cdot 0$ \\
\hline RHI21 & 5 & $40 \cdot 0$ & $25 \cdot 5$ & 6 & 14.20 & $21 \cdot 1$ \\
\hline RHI25 & 10 & $156 \cdot 0$ & 34.7 & 5 & $36 \cdot 10$ & $26 \cdot 1$ \\
\hline RHI40 & 5 & 247.0 & $40 \cdot 5$ & 5 & 31.90 & $24 \cdot 2$ \\
\hline RHI42 & 4 & $55 \cdot 2$ & 29.9 & 2 & $7 \cdot 50$ & $29 \cdot 5$ \\
\hline Total and mean & 38 & $100 \cdot 0$ & $30 \cdot 1$ & 29 & $20 \cdot 80$ & $23 \cdot 1$ \\
\hline \multicolumn{7}{|c|}{ River Frémur (FRE) } \\
\hline FRE04 & 5 & $105 \cdot 2$ & $27 \cdot 6$ & 3 & 11.00 & 14.0 \\
\hline FRE17 & 8 & $111 \cdot 0$ & $28 \cdot 0$ & 2 & 17.80 & $20 \cdot 1$ \\
\hline FRE18 & 7 & $86 \cdot 5$ & $24 \cdot 4$ & 4 & 9.69 & $15 \cdot 8$ \\
\hline FRE26 & 5 & $132 \cdot 0$ & $29 \cdot 2$ & 5 & $19 \cdot 30$ & $20 \cdot 5$ \\
\hline FRE45 & 15 & $136 \cdot 0$ & $25 \cdot 5$ & 13 & 30.70 & $21 \cdot 8$ \\
\hline FRE55 & 9 & $69 \cdot 2$ & $27 \cdot 6$ & 8 & $16 \cdot 30$ & $20 \cdot 5$ \\
\hline FRE56 & 3 & $88 \cdot 8$ & 21.9 & 4 & 8.00 & $16 \cdot 2$ \\
\hline Total and mean & 52 & 108.0 & $26 \cdot 5$ & 39 & $19 \cdot 60$ & $19 \cdot 5$ \\
\hline
\end{tabular}


not be fit to a normal distribution by parametric transformation, rank transformation (RT-1; Conover \& Iman, 1981) was chosen instead. On the other hand, square root transformation considerably increased the fit for the separate male and lemale data sets as inspected by Q-Q plots, and performing Shapiro-Wilks tests normality could no longer be rejected ( $P>0.05$, each).

As expected, there was a marked sexual dimorphism in A. crassus with females growing significantly larger $\left(F_{\mathrm{S} 1,140}=27 \cdot 1, P<0 \cdot 001\right)$ and heavier $\left(F_{\mathrm{SI}, 140}=115.4\right.$, $P<0.001)$ than males, whereas neither test among host infrapopulation nor sampling localities revealed significant contributions to overall sample variance in the three-level nested ANOVA at the 5\% level (Appendices 1 and 2). When dividing for sexes a priori, only the body mass of females showed marginally significant differentiation among infrapopulations within locations $\left(F_{\mathrm{S} 13,73}=1.80, P>\right.$ $0 \cdot 05$ ), represented in two-level ANOVA tables (Appendices 3 to 6). The unbalanced sampling did not influence the statistical values, thus, though Satterthwaite's correction did alter the d.f. and mean square values, no significant test was inferred.

\section{TEST FOR LINKAGE DISEQUILIBRIUM AND HARDY - WEINBERG EQUILIBRIUM}

According to an exact test for linkage disequilibrium among markers, neither comparison indicated significant deviations within sampling localities $(P>0.05$, each). While the FRE sample is in agreement with HWE at all four loci, neither marker matched HWE in the RHI, according to Fisher's exact test $(P<0.001$, each). The $F_{\text {IS }}$ values were consistent among marker loci (Table II), while they were not sex specific (Table III). Heterozygote deficits in the Rhine are evenly distributed over all microsatellite size classes at each locus, according to the Microchecker

TABLE II. Measurements of genetic diversity for Anguillicoloides crassus listed separately for sampling locality and microsatellite marker

\begin{tabular}{lcccrrrr}
\hline Location & $H_{\mathrm{E}(\mathrm{n} . \mathrm{b} .)}$ & $H_{\mathrm{O}}$ & $F_{\mathrm{IS}}$ & \multicolumn{1}{c}{$A$} & $\mathrm{AR}$ & S.D. & $95 \% \mathrm{CI}$ \\
\hline River Rhine & $(n=67)$ & & & & & & \\
AcrCT27 & 0.9453 & $0.7308^{*}$ & 0.2269 & 30.0 & 25.00 & & \\
AcrCT53 & 0.9610 & $0.7273^{*}$ & 0.2432 & 39.0 & 36.20 & & \\
AcrCT54 & 0.7608 & $0.5636^{*}$ & 0.2592 & 11.0 & 9.83 & & \\
AcrCA102 & 0.6272 & $0.4483^{*}$ & 0.2852 & 9.0 & 8.69 & & \\
Total & 0.8249 & $0.6175^{*}$ & 0.2514 & 22.3 & 19.90 & 13.10 & 12.90 \\
River Frémur $(n=91)$ & & & & & & \\
AcrCT27 & 0.8912 & 0.8839 & 0.0082 & 14.0 & 12.90 & & \\
AcrCT53 & 0.8979 & 0.8929 & 0.0056 & 19.0 & 16.60 & & \\
AcrCT54 & 0.7241 & 0.6786 & 0.0628 & 7.0 & 7.00 & & \\
AcrCA102 & 0.7717 & 0.7411 & 0.0397 & 9.0 & 7.62 & & \\
Total & 0.8221 & 0.7991 & 0.0280 & 12.3 & 11.00 & 4.54 & 4.45 \\
\hline
\end{tabular}

$n$, number; $H_{\mathrm{E}(\mathrm{n.b} .)}$, Nei's unbiased estimate of the expected heterozygosity; $F_{\mathrm{IS}}$, inbreeding coefficient calculated as $\left(H_{\Xi(n . b .)}-H_{\mathrm{O}}\right) / H_{\mathrm{E}(\mathrm{n} . \mathrm{b} .)} ;{ }^{*}$, significant deviation from Hardy-Weinberg expectations for $P=0.05 ; \mathrm{A}$, number of alleles; AR, allelic richness after rarefaction $(2 n=104$ genes). 
TABLE III. Single and averaged $F_{\text {IS }}$ values of Anguillicoloides crassus listed separately for sampling locality, marker and sex

\begin{tabular}{|c|c|c|c|c|c|c|c|c|}
\hline \multirow[b]{2}{*}{ Location } & \multirow[b]{2}{*}{ Sex } & \multicolumn{5}{|c|}{ Single locus $F_{\text {IS }}$} & \multirow[b]{2}{*}{ Mean \pm s.D. } & \multirow[b]{2}{*}{$95 \% \mathrm{Cl}$} \\
\hline & & $n$ & AcrCT27 & AcrCT53 & AcrCT54 & AcrCA102 & & \\
\hline \multirow[t]{2}{*}{ River Rhine } & Female & 38 & 0.316 & 0.283 & 0.203 & 0.301 & $0.276 \pm 0.050$ & 0.049 \\
\hline & Male & 29 & 0.131 & 0.309 & 0.260 & 0.462 & $0.291 \pm 0.137$ & 0.134 \\
\hline \multirow[t]{2}{*}{ River Frémur } & Female & 52 & 0.025 & 0.004 & -0.026 & 0.003 & $0.011^{*} \pm 0.012$ & 0.014 \\
\hline & Male & 39 & 0.048 & 0.040 & 0.080 & 0.085 & $0.063 \pm 0.023$ & 0.022 \\
\hline
\end{tabular}

$n$, number; $F_{\mathrm{IS}}$, inbreeding coefficient calculated as $\left(H_{\mathrm{E}(\text { n.b. })}-H_{\mathrm{O}}\right) / H_{\mathrm{E}(\text { n.b. })}$.

*, negative $F_{\mathrm{IS}}$-value excluded from calculating the mean.

TABLE IV. Excluding one microsatellite marker at a time, a jackknifing procedure depicts stable inbreeding and differentiation indices among infrapopulations within localities

\begin{tabular}{lccc}
\hline Jackknifing & $F_{\mathrm{IS}}$ & $F_{\mathrm{IT}}$ & $F_{\mathrm{ST}}$ \\
\hline River Rhine $(n=67)$ & & & \\
Without AcrCT53 & 0.268 & 0.279 & 0.0156 \\
Without AcrCT54 & 0.271 & 0.286 & 0.0198 \\
Without AcrCT27 & 0.283 & 0.297 & 0.0194 \\
Without AcrCA102 & 0.255 & 0.257 & 0.00270 \\
Mean \pm S.D. & $0.267 \pm 0.018$ & $0.278 \pm 0.025$ & $0.0133 \pm 0.0120^{\mathrm{s}, 5 \%}$ \\
River Frémur $(n=91)$ & & & \\
Without AcrCT53 & 0.0348 & 0.0368 & 0.00209 \\
Without AcrCT54 & 0.0149 & 0.0187 & 0.00391 \\
Without AcrCT27 & 0.0387 & 0.0349 & -0.00394 \\
Without AcrCA102 & 0.0197 & 0.0237 & 0.00411 \\
Mean \pm S.D. & $0.0259 \pm 0.0173$ & $0.0276 \pm 0.0131$ & $0.00183 \pm 0.00565^{\mathrm{NS}, 5 \%}$ \\
\end{tabular}

$s$, significantly different under the null model of 'zero' differentiation among infrapopulations; NS, not significantly different from 'zero'.

programme (van Oosterhout et al., 2004). Moreover, when applying a jackknifing procedure, removing one locus at a time, all loci contributed similarly to the given $F_{\text {IS }}$ (Table IV). Thus, the deviations from HWE are independent of null alleles and other marker defects but are connected to a population-level effect.

\section{PAIR-WISE RELATEDNESS WITHIN INFRAPOPULATIONS}

When assessing the pair-wise relatedness $\left(r_{x y}\right)$ within infrapopulations for each locality, the samples from the Rhine were significantly different from random expectations, with a slightly positive infrapopulations average of 0.025 , which was situated in the extreme right-hand tail of the distribution $[P<0.001$; Fig. 2(a)]. On the contrary, the observed value from the Frémur was slightly negative, but not significantly distinct from the median of -0.010 ('no pair-wise relatedness') and clustered within the distribution $[P>0.05$; Fig. 2(b)]. 
(a)

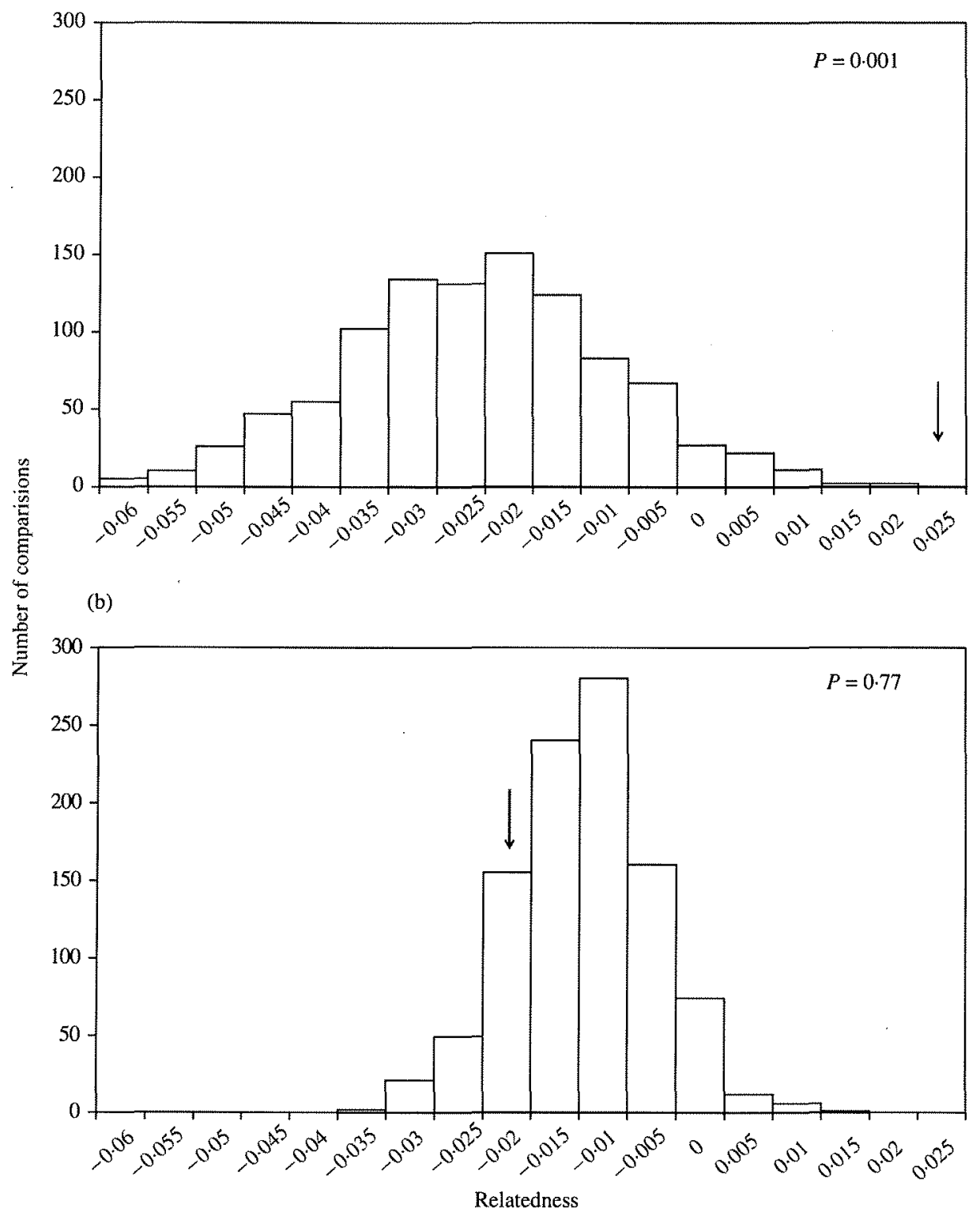

FIG. 2. Comparing simulated and observed (l) measurements of pair-wise relatedness $r_{\mathrm{xy}}$ (Queller \& Goodnight, 1989) using SPAGeDi version $1.2 \mathrm{~g}$ (Hardy \& Vekemans, 2002). Means of infrapopulation relatedness for (a) the Rhine River $(n=67 ; P<0.001)$ and (b) Frémur River $(n=91 ; P>0.05)$, respectively.

\section{HIERARCHICAL $F$-STATISTICS}

A locus-by-locus AMOVA indicated that the component adding to the overall genetic variance least was the variance among infrapopulations within regions $(0.58 \%)$, whereas $4.66 \%$ of the variance is confined among regions. The highest 
values of genetic variation were found at the individual level, where genetic variance was confined within the individuals $(84.7 \%)$ and among individuals within infrapopulations $(10.0 \%)$. The average fixation indices over all loci accumulated to the following values $\Phi_{\mathrm{IS}}=0.1058(P<0.001) ; \Phi_{\mathrm{SC}}=0.0061(P>0.05) ; \Phi_{\mathrm{CT}}=0.0466$ $(P<0.001) ; \Phi_{\mathrm{IT}}=0.1527(P<0.001)$, where $P$ values $<0.05$ depict significant differentiation at the given hierarchical level. From these values, it is clear that all but fixation index $\Phi_{\mathrm{SC}}$ and its respective variance component differ highly significantly from a randomly generated distribution given the data. A further analysis of among infrapopulations within localities revealed a low but significant $F_{\mathrm{ST}}=0.014$ $(P<0.05)$ in the Rhine. On the contrary, the Frémur sample was not differentiated among infrapopulations $\left(F_{\mathrm{ST}}=0.0007, P>0.05\right)$.

\section{TESTS FOR IMMIGRATION AND SIMULATION OF THE WAHLUND EFFECT}

According to a FCA, the only split of the data set occurs along the first axis, separating both localities (Fig. 3). While most samples cluster within close range of their respective group members, parts of the Rhine samples scatter widely in variance space. Consequently, assuming population structure, a high proportion of admixed individuals in the Rhine River is apparent (Fig. 4). Using $Q$ estimates in Structure, only one third of individuals appear to have a pure genetic background (Fig. 5). Several single individuals appear to have been introduced as first-generation migrants into the Rhine River. This hypothesis could be verified using Geneclass.

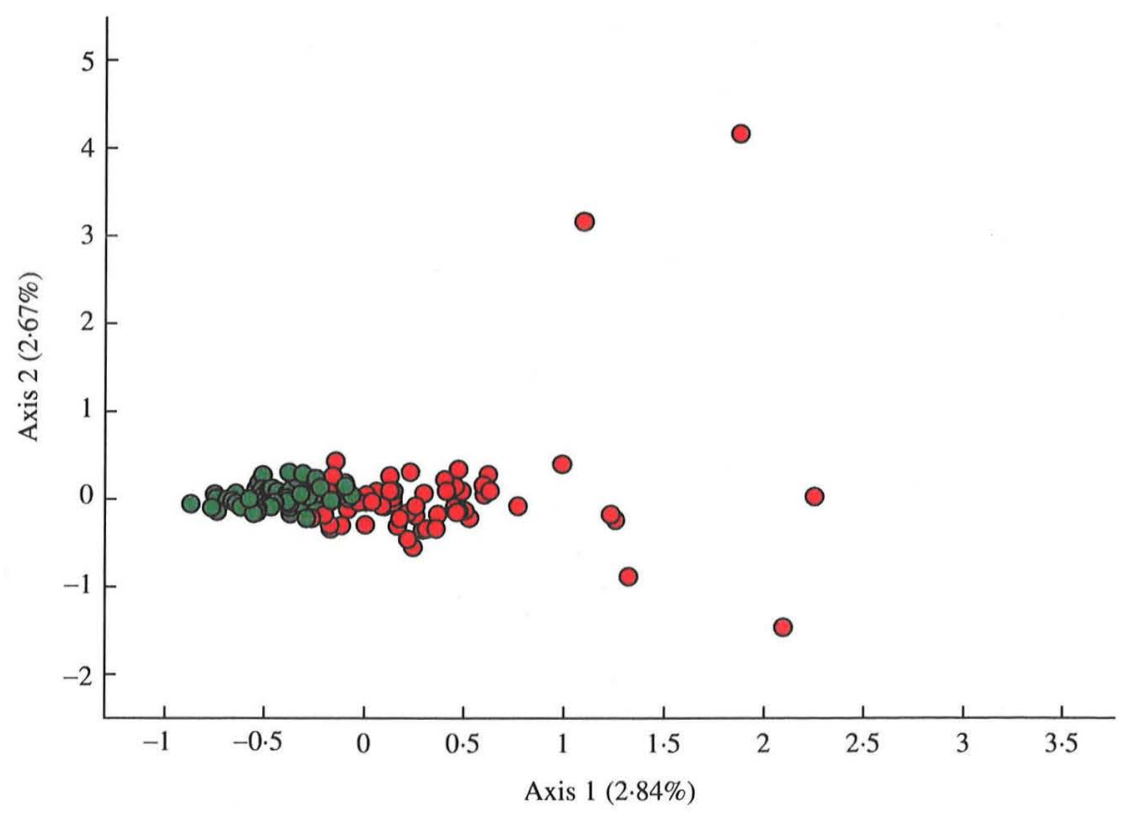

FIG. 3. Factorial component analysis highlighting individual clustering of specimens of Anguillicoloides crassus for the first two dimensions of variance. The only split of the data is apparent among the two sampling localities [Frémur $(O)$ and Rhine $(O)$ Rivers]. While most individuals cluster in close vicinity, several outliers indicate differentiation within the Rhine sample. 


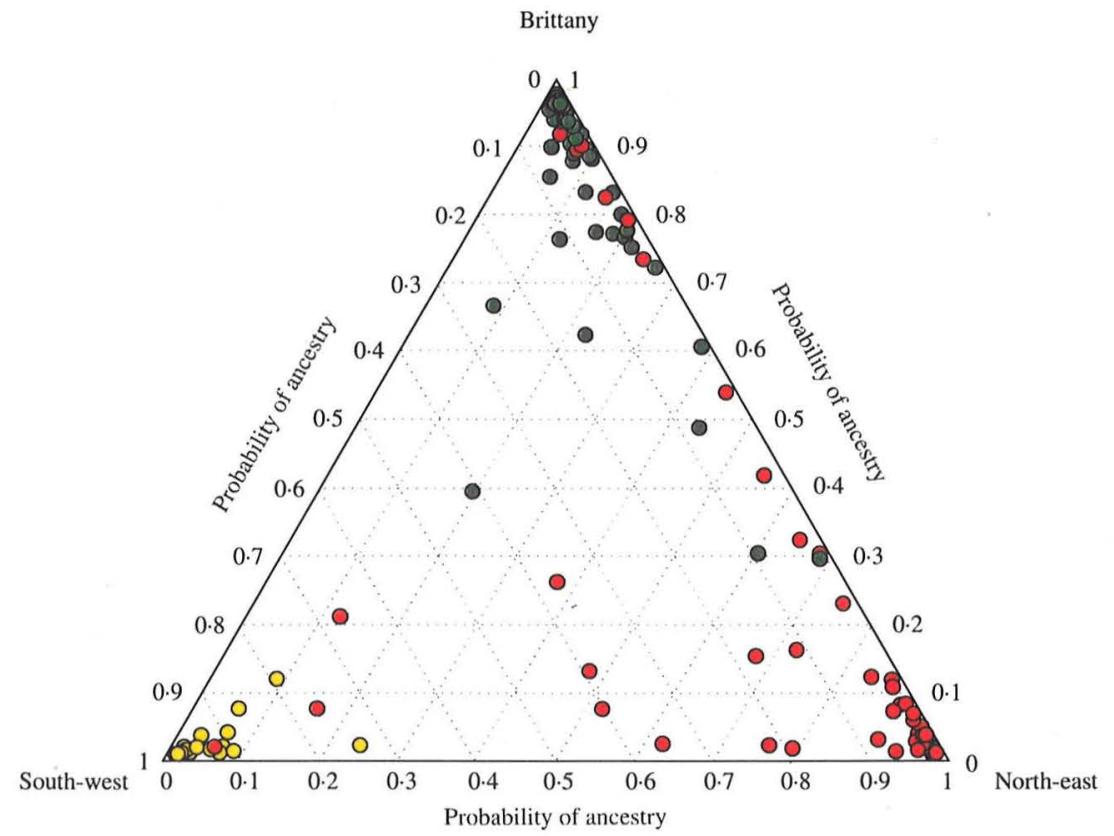

FIG. 4. Levels of admixture of Anguillicoloides crassus specimens within and among European sampling localities [Frémur $(O)$ and Rhine $(O)$ Rivers and Camargue $(O)$ ] depicted by a ternary plot of ancestry proportions $(Q)$ according to previously detected population clusters in Europe (Wielgoss et al., 2008). Pure ancestry is indicated for corner positions, whereas admixed states are present at intermediate ranges.

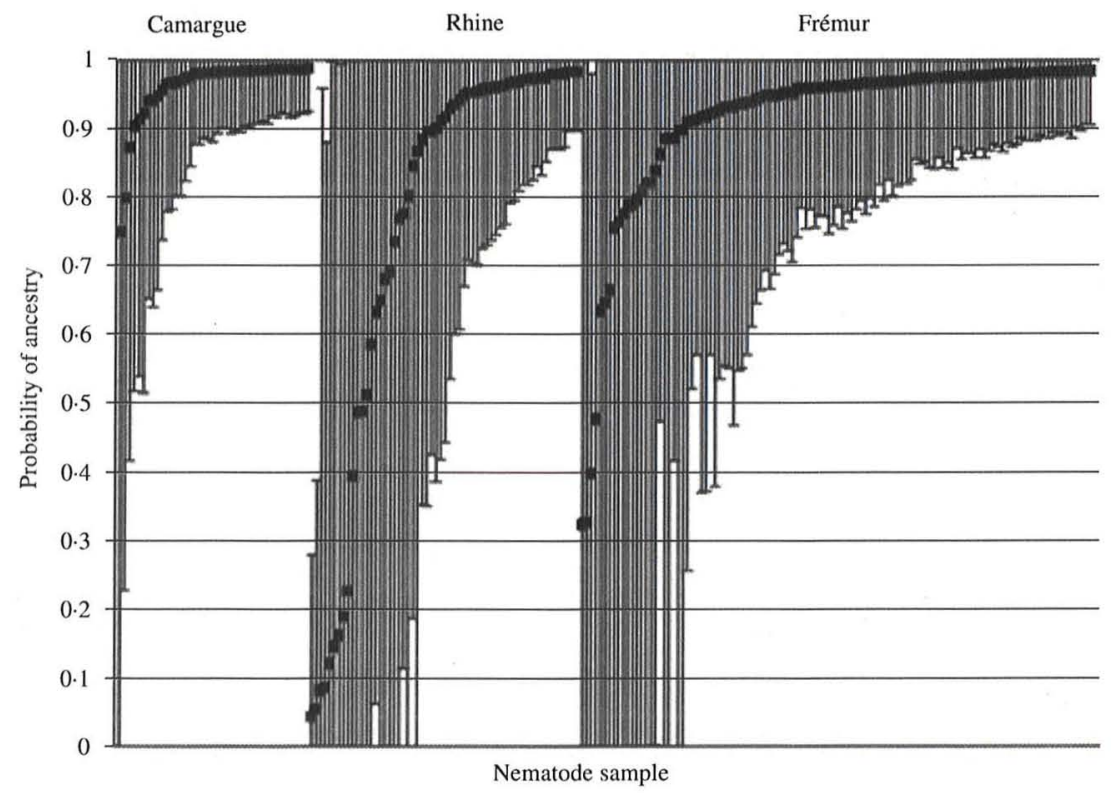

FIG. 5. Representation of individual admixture proportions $Q$ of specimens of Anguillicoloides crassus within European sampling localities derived from the programme Structure version 2.2 (Pritchard et al., 2000). The maximum $\left(Q_{\max }=1.0\right)$ on the $y$-axis represents pure origin for each population sample, i.e. Camargue, Rhine River and the Frémur River. The minimum value $Q_{\min }=0$ highlights expatriates. Error bars are s.D. 
While there is no single instance of immigration in the Frémur River, the presence of three first-generation migrants is supported for the Rhine River (Table V). Applying a simulation, the impact of an artificially introduced Wahlund effect was inspected. The settings were chosen according to knowledge of recent invasion history. After simulating allelic changes in 10 populations of 100 individuals for 100 generations, the genetic diversity dropped continuously to final levels in the range of $0.49-0.86$, when starting with 50 alleles per locus. This finding is consistent with real data for microsatellite markers (Wielgoss et al., 2008). In the case of separate populations, $F_{\text {IS }}$ values were not much different from 0 in either population and deviated by maximally $0 \cdot 01$. On the other hand, the $F_{S T}$ value among populations approached 0.20 for single markers. On the contrary, lumping of the separate populations into one big mixed population of 1000 individuals, i.e. introducing a Wahlund effect, leads to $F_{\mathrm{IS}}$ values of the same range as found in the real data, $0 \cdot 150-0.221$, which is correlated with a small increase in $F_{\mathrm{ST}}$, and highly increased genetic diversity between 0.932 and 0.940 .

\section{DISCUSSION}

\section{EVIDENCE FOR THE WAHLUND EFFECT AND FIRST-GENERATION MIGRANTS}

In this study, it is shown that available genetic tools for the parasite A. crassus (Wielgoss et al., 2007) are sensitive to different immigration rates into local A. anguilla stocks for two separated river systems. While random mating of nematodes is apparent in naturally recruiting hosts retrieved from the River Frémur, the Rhine sample shows strong deviation from HWE consistent over all loci and between sexes. As there is no sign for marker-specific issues to explain this observation, several independent measures give reasonable evidence for the detection of a Wahlund effect (Hartl \& Clark, 1997), most likely as a direct consequence of annual restocking of infected $A$. anguilla. First, the highly polymorphic microsatellite markers show consistent patterns of high heterozygote deficiency (average $F_{\mathrm{IS}}=0.25$ ), and markers contributing most to the overall significant $F_{\mathrm{ST}}$ are also the ones showing the highest $F_{\text {IS values }}(r=0.953)$. This pattern is absent in the Frémur River $(r=-0 \cdot 855)$. Second, genetic differentiation among infrapopulations in the Rhine River is markedly higher than between samples on opposite sides of the Baltic Sea (Wielgoss et al., 2008), while allelic richness corrected for sample size is double the number found in the Frémur sample. Third, the presence of first-generation migrants in the Rhine River is highly supported using both individual clustering and assignment approaches based on Bayesian statistics and marks the recent influx of genetic signatures mainly from south-western parts of the parasite's distribution area, paralleling the known distribution path of captured small $A$. anguilla for restocking purposes in Europe. As a side note, both statistics, $L_{\text {home }}$ and $\Lambda$, identified the same suspect individuals for the given computation method used. Because the latter formula is most appropriate if all relevant source populations have been sampled (Paetkau et al., 2004), it follows that the European invasion is reasonably well represented by the sampling in Wielgoss et al. (2008). Fourth, an artificially introduced Wahlund effect using simulated data from Easypop version 1.7 (Balloux, 2001) revealed patterns already 
TABLE V. Detection of first-generation migrants from a baseline data set comprising 362 Anguillicoloides crassus individuals of 11 European sampling localities (Wielgoss et al., 2008). Rannala \& Mountain's (1997) Bayesian computation method was used, and two different likelihood statistics: $-\log _{10}\left(L_{\text {home}}\right)$ and $\Lambda$ (Paetkau et al., 2004) as given in Geneclass version 2.0h (Piry et al., 2004) were computed. Probabilities of being a resident were performed using the sampling method of Paetkau et al. (2004), comparing observed genotypes with 10000 simulated genotypes

\begin{tabular}{lcclrcc}
\hline Individual & $\Lambda$ & $P$ & \multicolumn{1}{c}{ Assigned to } & $-\log _{10}\left(L_{\text {home }}\right)$ & $P$ & Assigned to \\
\hline Rhine04c & 0.239 & $<0.05$ & North Baltic Sea (ALA) & 12.176 & $<0.05$ & North Baltic Sea (ALA) \\
Rhine04d & 1.780 & $<0.01$ & North Irish Sea (SHA) & 12.333 & $<0.01$ & North Irish Sea (SHA) \\
Rhine06e & 0.809 & $>0.05$ & North Irish Sea (NEA) & 7.531 & $>0.05$ & North Irish Sea (NEA) \\
Rhine12h & 0.332 & $>0.05$ & West Breton Sea (VIL) & 10.521 & $>0.05$ & West Breton Sea (VIL) \\
Rhine21f & 1.569 & $>0.05$ & North Irish Sea (NEA) & 8.129 & $>0.05$ & North Irish Sea (NEA) \\
Rhine25n & 1.604 & $<0.05$ & North Irish Sea (SHA) & 10.342 & $<0.05$ & North Irish Sea (SHA) \\
Rhine40h & 0.535 & $>0.05$ & South Mediterranean Sea (TIB) & 9.218 & $>0.05$ & South Mediterranean Sea (TIB)
\end{tabular}

$\Lambda=-\log _{10} / L_{\text {home }}-\log _{10} L_{\text {max }} ;$ ALA, Åland Island (Finland); SHA, Shannon (Ireland); NEA, Neagh (Ireland); VIL, Vilaine (France); TIB, Tiber (Italy). 
observed in the real data set, above all, 1) rapidly increasing $F_{\text {IS }}$ values over generations and consistent over loci and 2) inflated allelic richness. This finding is in line with the present results and immigration of infected $A$. anguilla are probably reflected in the parasite's genetic signals.

A similar pattern of HWE deviation has previously been detected in a parasite host system comprising a marine anguilliform species, Conger conger (L.), and its trematode parasite, Lecithochirium fusiforme. Based on six polymorphic allozyme makers, Vilas et al. (2003) inferred the influence of a Wahlund effect due to temporal mixing of divergent parasite populations in the unstructured marine habitats of $C$. conger, because of highly correlated $F_{\mathrm{ST}}$ and $F_{\mathrm{IS}}$ values. The authors attributed this effect to the high mobility of known transport fish hosts and the possibility of low effective population sizes in parasite populations due to low survival in a coarse-grained parasite environment (Price, 1977).

\section{INTERPRETATION OF HIERARCHICAL ANALYSES}

The nesting of nematodes within hosts allowed for statistical analyses of both morphometric and genetic measurements in a hierarchical manner. As a drawback, the missing replication at the highest level (sampling localities) did not allow for statistically determining if nematodes responded to stocking in general or only in the specific case of the Rhine samples. First, an AMOVA revealed a significant differentiation of the two sampling localities of $\Phi_{\mathrm{CT}}=0.0466(P<0.001)$. The value is intermediate to the analogous and also highly significant $\theta_{\mathrm{ST}}$ measures reported in Wielgoss et al. $(2008)$ for Brittany $\left(\theta_{\mathrm{ST}}=0.042\right)$ and the easternmost Baltic Sea samples $\left(\theta_{\mathrm{ST}}=0.068-0.077\right)$. This pattern is in line with the Rhine's intermediate position among these regions and could be even lower than expected due to the presence of individuals with Brittany signatures. The elevated inbreeding index of $\Phi_{I S}=0.11(P<0.001)$ is probably derived from the Rhine's high inbreeding index, whereas the non-significant differentiation at the level 'among infrapopulations within regions' $\left(\Phi_{\mathrm{SC}}=0.0061 ; P>0.05\right)$ is contrasted by the presence of higher than expected pairs of related parasites within hosts in the Rhine River: here, the average pair-wise relatedness is positive and the null model of 'all unrelated' individuals within infrapopulations can be refuted with high confidence $(P<0.001)$.

This is a strong argument for initial non-random mixing of related nematodes in the same infrapopulations due to the translocation event of infected hosts into a new habitat, in which further infections are acquired. On the contrary, there is no good evidence for frequent inbreeding, non-sexual propagation or clumped transmission of individual nematodes into single hosts, because the average relatedness is only marginally higher than zero $\left(r_{x y}=0.02\right)$ and under natural recruitment (Frémur River), random mating is observed within hosts. Above all, the mixing of nematodes is expected to be random, given the host's indirect life cycle. If infrequent non-random mixing explains the pattern, one possibility could be the transmission of related larval aggregates into the intermediate hosts, such as is known for parasite-host systems comprising sheep and frog final hosts (Boag et al., 1989; Zelmer et al., 1999). This would also require joint proper development and survival until reaching a novel final host (Fig. 1).

Most of the variance in both both $L_{\mathrm{T}}$ and $M_{\mathrm{T}}$ was explained by the sexual dimorphism among males and females. In contrast, there is no or only weak support for 
differentiation on other hierarchical levels such as among 'host infrapopulations', or 'local populations', either including or separating for both sexes in the nANOVA. Interestingly, despite the ineffective immunological response against the parasite (Knopf \& Lucius, 2008; Knopf et al., 2008), the females' total body masses differ marginally significantly among hosts at the $\alpha=10 \%$ level with $P=0.060$. This trend appears to be relevant as body measurements among males are not differentiated either among hosts or regions, and female lengths are also not affected. Earlier reports on density-dependent control of the number of gravid females within infrapopulations might be responsible for the observed pattern (Ashworth \& Kennedy, 1999). In this case, the number of gravid females might be biased in response to co-inhabitants or nutritional status of the host.

\section{CRITICAL REMARKS TO SAMPLING DESIGN AND APPLICABILITY}

Using co-dominant genetic markers, the two differently managed systems clearly revealed a measurable genetic difference by means of the parasite tag of the fish. Thus, the sensitivity of the marker system appears suitable to indicate restocking and fish translocation. The lack of replication of the two treatments (restocking $v$. natural recruitment), however, did not allow for general conclusions in this study by means of its parasite, $A$. crassus. Moreover, it was not possible to retrieve direct information on the actual origin of the small $A$. anguilla used for restocking, and thus it remains to be tested whether farms or natural habitats of glass eels and elvers of $A$. anguilla are the major source of primary infection.

Since the detection of stocking is unnecessary if strictly regulated, and stock managers must rely on quantitative measures for making decisions (Dekker, 2009), the direct application of the present method is most suitable for cases in which, 1) previously uninfected areas are invaded (such as in the case of the Island of Réunion; Sasal et al., 2008), 2) an unknown source population is screened for its most likely region of origin (such as in the case of the European invasion history; Wielgoss et al., 2008) and 3) when explicit stocking events went unrecognized. The screening of escaped migrant $A$. anguilla in the open ocean represents another, highly interesting field but is hampered by the fact that migrants have never been observed free in the open ocean (Dekker, 2009).

This study was supported by a studentship from the Landesgraduiertenförderung BadenWürttemberg to SW. We owe thanks to H. Taraschewski and U. Weclawski (TH Karlsruhe) for contributing samples from the Rhine. Furthermore, we thank J. Guillouët, J.-M. Caraguel and A. Legault from FISHPASS in Rennes (France) for offering logistic help with on-site sampling in the Frémur, as well as P. Lafaille and A. Baisez for kindly providing us with laboratory space and equipment at the University of Rennes. We thank K. Elmer and three reviewers for helpful comments on earlier versions of the manuscript.

\section{References}

Aarestrup, K., Økland, F., Hansen, M. M., Righton, D., Gargan, P., Castonguay, M., Bernatchet, L., Howey, P., Sparholt, H., Pedersen, M. I. \& McKinley, R. S. (2009). Oceanic spawning migration of the European eel (Anguilla anguilla). Science 325, 1660.

Ashworth, S. T. \& Kennedy, C. R. (1999). Density-dependent effects on Anguillicola crassus (Nematoda) within its European eel definitive host. Parasitology 118, 289-296 
Balloux, F. (2001). EASYPOP (Version 1.7): a computer program for population genetics simulations. Journal of Heredity 92, 301-302.

Boag, B., Topham, P. B. \& Webster, R. (1989). Spatial distribution on pasture of infective larvae of the gastro-intestinal nematode parasites of sheep. International Journal for Parasitology 19, 681-685.

Bruford, M. W., Hanotle, O., Brookfield, J. F. Y. \& Burke, T. (1992). Multi-locus and singlelocus DNA fingerprinting. In Molecular Analysis of Populations (Hoelzel, A. R., ed.), pp. 283-336. New York, NY: Oxford University Press.

Bush, A. O., Lafferty, K. D., Lotz, J. M. \& Shostak, A. W. (1997). Parasitology meets ecology on its own terms: Margolis et al. revisited. Journal of Parasitology 83, 575-583.

COM. (2007). Establishing measures for the recovery of the stock of European eel. Council Regulation (EC) No 1100/2007. Official Journal of the European Union L 248, 17-23.

Conover, W. J. \& Iman, R. L. (1981). Rank transformations as a bridge between parametric and nonparametric statistics. American Statistician 35, 124-129.

Criscione, C. D., Cooper, B. \& Blouin, M. S. (2006). Parasite genotypes identify source populations of migratory fish more accurately than fish genotypes. Ecology 87, 823-828.

Dannewitz, J., Maes, G. E., Johansson, L., Wickström, H., Volckaert, F. A. M. \& Järvi, T. (2005). Panmixia in the European eel: a matter of time. Proceedings of the Royal Society $B$ 272, $1129-1137$.

Dawson, K. \& Belkhir, K. (2001). A Bayesian approach to the identification of panmictic populations and the assignment of individuals. Genetics Research 78, 59-77.

Dekker, W. (2000). The fractal geometry of the European eel stock. ICES Journal of Marine Science 57, 109-121.

Dekker, W. (2003). Did lack of spawners cause the collapse of the European eel, Anguilla anguilla? Fisheries Management and Ecology 10, 365-376.

Dekker, W. (2008). Coming to grips with the eel stock slip-sliding away. American Fisheries Society Symposium 62, 335-355.

Dekker, W. (2009). A conceptual management framework for the restoration of the declining European eel stock. In Eels at the Edge: Science, Status, and Conservation Concerns (Casselman, J. M. \& Cairns, D. K., eds), pp. 3-19. American Fisheries Society, Symposium $\mathbf{5 8 .}$

Excoffier, L., Smouse, P. \& Quattro, J. (1992). Analysis of molecular variance inferted from metric distances among DNA haplotypes: applications to human mitochondrial DNA restriction data. Genetics 131, 479-491.

Excoffier, L., Laval, G. \& Schneider, S. (2005). Arlequin ver. 3.0: an integrated software package for population genetics data analysis. Evolutionary Bioinformatics Online 1, $47-50$.

Falush, D., Stephens, M. \& Pritchard, J. K. (2003). Inference of population structure using multilocus genotype data: linked loci and correlated allele frequencies. Genetics 164, $1567-1587$.

Falush, D., Stephens, M. \& Pritchard, J. K. (2007). Inference of population structure using multilocus genotype data: dominant markers and null alleles. Molecular Ecology Notes $7,574-578$.

Feunteun, E. (2002). Restoration and management of the European eel: an impossible bargain? Ecological Engineering 18, 575-591.

Gaylor, D. W. \& Hopper, F. N. (1969). Estimating the degrees of freedom for linear combinations of mean squares by Satterthwaite's formula. Technometrics 11, 691-705.

Goudet, J. (1995). FSTAT (Version 1.2): a computer program to calculate F-statistics. Journal of Heredity 86, 485-486.

Hardy, O. J. \& Vekemans, X. (2002). SPAGeDi: a versatile computer program to analyse spatial genetic structure at the individual or population levels. Molecular Ecology Notes $2,618-620$.

Hartl, D. L. \& Clark, A. G. (1997). Principles of Population Genetics, 3rd edn. Sunderland, MA: Sinauer Associatives, Inc.

Herrington, W. C., Bearse, H. M. \& Firth, F. E. (1939). Observations on the life history, occurrence and distribution of the redfish parasite Sphyrion lumpi. United States Bureau of Fisheries Report 5, 1-18. 
Kalinowski, S. T. (2005). HP-RARE 1.0: a computer program for performing rarefaction on measures of allelic richness. Molecular Ecology Notes 5, 187-189.

Kirk, R. (2003). The impact of Anguillicola crassus on European eels. Fisheries Management and Ecology 10, 385-394.

Knopf, K. \& Lucius, R. (2008). Vaccination of eels (Anguilla japonica and Anguilla anguilla) against Anguillicola crassus with irradiated L3. Parasitology 135, 633-640.

Knopf, K., Madriles Helm, A., Lucius, R., Bleiss, W. \& Taraschewski, H. (2008). Migratory response of European eel (Anguilla anguilla) leukocytes to the eel swimbladder nematode Anguillicola crassus. Parasitology Research 102, 1311-1316.

Kristmundsson, A. \& Helgason, S. (2007). Parasite communities of eels Anguilla anguilla in freshwater and marine habitats in Iceland in comparison with other parasite communities of eels in Europe. Folia Parasitologica (Praha) 54, 141-153.

Lintas, C., Hirano, J. \& Archer, S. (1998). Genetic variation of the European eel (Anguilla anguilla). Molecular Marine Biology and Biotechnology 7, 263-269.

MacKenzie, K. (2002). Parasites as biological tags in population studies of marine organisms: an update. Parasitology 124, S153-S163.

Maes, G. E. \& Volckaert, F. A. M. (2002). Clinal genetic variation and isolation by distance in the European eel Anguilla anguilla (L.). Biological Journal of the Linnean Society $77,509-521$.

Moravec, F. (2006). Dracunculoid and Anguillicoloid Nematodes Parasitic in Vertebrates. Prague: Academia.

Moravec, F. \& Taraschewski, H. (1988). Revision of the genus Anguillicola Yamaguti, 1935 (Nematoda: Anguillicolidae) of the swimbladder of eels, including descriptions of two new species, A. novaezelandiae sp.n. and A. papernai sp.n. Folia Parasitologica 35, $125-146$.

Moriarty, C. (1986). Riverine migration of young eels (Anguilla anguilla L.). Fisheries Research 4, 43-58.

Mosquera, J., Gómez-Gesteira, M. \& Pérez-Villar, V. (2000). Using parasites as biological tags of fish populations: a dynamical model. Bulletin of Mathematical Biology 62, $87-99$.

Nieberding, C. M. \& Olivieri, I. (2007). Parasites: proxies for host genealogy and ecology? Trends in Ecology \& Evolution 22, 156-165.

van Oosterhout, C., Hutchinson, W. F., Wills, D. P. M. \& Shipley, P. (2004). Micro-Checker: software for identifying and correcting genotyping errors in microsatellite data. Molecular Ecology Notes 4, 535-538.

Paetkau, D., Slade, R., Burden, M. \& Estoup, A. (2004). Direct, real-time estimation of migration rate using assignment methods: a simulation-based exploration of accuracy and power. Molecular Ecology 13, 55-65.

Piry, S., Alapetite, A., Cornuet, J.-M., Paetkau, D., Baudouin, L. \& Estoup, A. (2004). GeneClass2: a software for genetic assignment and first generation migrants detection. Journal of Heredity 95, 536-539.

Price, P. W. (1977). General concepts on the evolutionary biology of parasites. Evolution 31, $405-420$.

Pritchard, J. K., Stephens, M. \& Donnelly, P. (2000). Inference of population structure using multilocus genotype data. Genetics 155, 945-959.

Queller, D. C. \& Goodnight, K. F. (1989). Estimating relatedness using genetic markers. Evolution 43, 258-275.

Rannala, B. \& Mountain, J. L. (1997). Detecting immigration by using multilocus genotypes. Proceedings of the National Academy of Sciences of the United States of America 94, 9197-9201.

Raymond, M. \& Rousset, F. (1995). GENEPOP (version 1.2): population genetics software for exact tests and ecumenicism. Journal of Heredity 86, 248-249.

Sasal, P., Taraschewski, H., Valade, P., Grondin, H., Wielgoss, S. \& Moravec, F. (2008). Parasite communities in eels of the Island of Reunion (Indian Ocean): a lesson in parasite introduction. Parasitology Research 102, 1343-1350.

Simon, J., Dörner, H. \& Richter, C. (2009). Growth and mortality of European glass eels Anguilla anguilla marked with oxytetracycline and alizarin red. Journal of Fish Biology 74, 289-295. doi: $10.1111 / \mathrm{j} .1095-8649.2008 .02117 . \mathrm{x}$ 
Sokal, R. R. \& Rohlf, F. J. (1995). Biometry, 3rd edn. New York, NY: W. H. Freeman.

Tsukamoto, K., Aoyama, J. \& Miller, M. J. (2002). Migration, speciation, and the evolution of diadromy in anguillid eels. Canadian Journal of Fisheries and Aquatic Sciences 59, 1989-1998.

Vilas, R., Paniagua, E. \& Sanmartín, M. L. (2003). Genetic variation within and among infrapopulations of the marine digenetic trematode Lecithochirium fusiforme. Parasitology 126, 465-472.

Westin, L. (1990). Orientation mechanisms in migrating European silver eel (Anguilla anguilla): temperature and olfaction. Marine Biology 106, 175-179.

Westin, L. (2003). Migration failure in stocked eels Anguilla anguilla. Marine Ecology Progress Series 254, 307-311.

Wickström, H. (2001). Stocking as a sustainable measure to enhance eel populations. Doctoral Thesis, Stockholm University, Stockholm, Sweden.

Wielgoss, S., Sanetra, M., Meyer, A. \& Wirth, T. (2007). Isolation and characterization of short tandem repeats in an invasive swimbladder nematode, parasitic in Atlantic freshwater eels, Anguillicola crassus. Molecular Ecology Notes 7, 1051-1053.

Wielgoss, S., Taraschewski, H., Meyer, A. \& Wirth, T. (2008). Population structure of the parasitic nematode Anguillicola crassus, an invader of declining North Atlantic eel stocks. Molecular Ecology 17, 3478-3495.

Wirth, T. \& Bernatchez, L. (2001). Genetic evidence against panmixia in the European eel. Nature 409, 1037-1040.

Wirth, T. \& Bernatchez, L. (2003). Decline of North Atlantic eels: a fatal synergy? Proceedings of the Royal Society $B$ 270, 681-688.

Wirth, T., Meyer, A. \& Achtman, M. (2005). Deciphering host migrations and origins by means of their microbes. Molecular Ecology 14, 3289-3306.

Zelmer, D. A., Wetzel, E. J. \& Esch, G. W. (1999). The role of habitat in structuring Halipegus occidualis metapopulations in the green frog. Journal of Parasitology 85, $19-24$.

\section{Electronic References}

ICES. (1976). International Council for the Exploration of the Sea. First report of the working group on stocks of the European eel. ICES C.M. 1976/M,2. Available at http://www. fao.org/docrep/009/ae991b/AE991B00.htm\#TOCE

Moriarty, C. (1996). Glass eel supply and demand in Europe in 1995 EIFAC (FAO) Working Party on Eel: Report to ICES. Available at ftp://ftp.fao.org/docrep/fao/007/w5471e/ w5471e00.pdf

APPENDIX 1. Table of a mixed three-level nested ANOVA of total body mass including both sexes in adult nematodes, Anguillicoloides crassus, based on rank-transformed data (RT-1; Conover \& Iman, 1981)

\begin{tabular}{llrcccccccc}
\hline $\begin{array}{l}\text { Source of } \\
\text { variation }\end{array}$ & $\begin{array}{c}\text { Effect } \\
\text { attribute }\end{array}$ & d.f. & SS & MS & $F_{\mathrm{S}}$ & $P$ & $F_{\text {S }}$ & $P^{\prime}$ & $F_{\text {lme }}$ & $P_{\text {Ime }}$ \\
\hline Locations & Fixed & 1 & 1047 & 1047 & 0.29 & 0.60 & 0.26 & 0.62 & 0.49 & 0.50 \\
Infrapopulations & Random & 13 & 46839 & 3603 & 0.03 & 1.00 & 0.36 & 0.88 & & \\
Sex & Fixed & 1 & 125898 & 125898 & 115.4 & $<0.0001$ & & & 118.5 & $<0.0001$ \\
Residuals & Random & 142 & 154889 & 1091 & & & & & & \\
Total & & 157 & 328673 & & & & & & &
\end{tabular}

SS, sum of squares; MS, mean squares; $F_{\mathrm{S}}, F_{\text {-statistic; } F} F_{S}$, derived $F$-statistic using Satterthwaite's approximation, as devised by Sokal \& Rohlf (1995), for which all criteria were met; $F_{\text {lme }}, F$-value inferred from a linear mixed effect model using REML technique; $P$, probability given $F_{S} ; P^{\prime}$, probability given derived $F_{S}^{\prime} ; P_{\text {Ime }}$, probability given $F_{\text {lme }}$. 
APPENDIX 2. Table of a mixed three-level nested ANOVA of total lengths including both sexes in adult nematodes, Anguillicoloides crassus, based on rank-transformed data (RT-1; Conover \& Iman, 1981)

\begin{tabular}{llrcccccccc}
\hline $\begin{array}{l}\text { Source of } \\
\text { variation }\end{array}$ & $\begin{array}{c}\text { Effect } \\
\text { attribute }\end{array}$ & d.f. & SS & MS & $F_{\mathrm{S}}$ & $P$ & $F_{\text {S }}^{\prime}$ & $P^{\prime}$ & $F_{\text {line }}$ & $P_{\text {line }}$ \\
\hline Locations & Fixed & 1 & 12177 & 12177 & 3.49 & 0.085 & 3.13 & 0.11 & 2.74 & 0.12 \\
Infrapopulations & Random & 13 & 45391 & 3492 & 0.08 & 1.00 & 0.76 & 0.73 & & \\
Sex & Fixed & 1 & 43495 & 43495 & 27.10 & $<0.0001$ & & & 29.10 & $<0.0001$ \\
Residuals & Random & 142 & 227616 & 1603 & & & & & & \\
Total & & 157 & 328679 & & & & & & &
\end{tabular}

SS, sum of squares; MS, mean squares; $F_{S}, F$-statistic; $F_{S}^{\prime}$, derived $F$-statistic using Satterthwaite's approximation, as devised by Sokal \& Rohlf (1995), for which all criteria were met; $F_{\text {lme }}, F$-value inferred from a linear mixed effect model using REML technique; $P$, probability given $F_{\mathrm{S}} ; P^{\prime}$, probability given derived $F_{S}^{\prime} ; P_{\text {lme }}$, probability given $F_{\text {lme }}$.

APPENDIX 3. Table of a mixed two-level nested ANOVA of total body mass of female adult nematodes, Anguillicoloides crassus, based on square root-transformed data

\begin{tabular}{llccccccccc}
\hline Source of variation & $\begin{array}{c}\text { Effect } \\
\text { attribute }\end{array}$ & d.f. & SS & MS & $F_{\mathrm{S}}$ & $P$ & $F_{\text {S }}^{\prime}$ & $P^{\prime}$ & $F_{\text {Ime }}$ & $P_{\text {lme }}$ \\
\hline Locations & Fixed & 1 & 12.96 & 13 & 0.45 & $>0.05$ & 0.40 & 0.54 & 0.75 & $>0.05$ \\
Infrapopulations & Random & 13 & 374.7 & 29 & 1.8 & $>0.05$ & & & & \\
Residuals & Random & 75 & 1203.1 & 16 & & & & & & \\
Total & & 89 & 1590.8 & & & & & & & \\
\hline
\end{tabular}

SS, sum of squares; MS, mean squares; $F_{\mathrm{S}}, F$-statistic; $F^{\prime}$ S, derived $F$-statistic using Satterthwaite's approximation, as devised by Sokal \& Rohlf (1995), for which all criteria were met; $F_{\text {Ime }}, F$-value inferred from a linear mixed effect model using REML technique; $P$, probability given $F_{\mathrm{S}} ; P^{\prime}$, probability given derived $F^{\prime}$; $P_{\mathrm{lm}}$, probability given $F_{\mathrm{Ime}}$.

APPENDIX 4. Table of a mixed two-level nested ANOVA (Sokal \& Rohlf, 1995) depicting hierarchical distribution of variance of total lengths in adult female nematodes, Anguillicoloides crassus, based on untransformed data

\begin{tabular}{llrrrrrrrrr}
\hline Source of variation & $\begin{array}{c}\text { Effect } \\
\text { attribute }\end{array}$ & d.f. & \multicolumn{1}{c}{ SS } & MS & $F_{\mathrm{S}}$ & $P$ & $F_{\text {s }}^{\prime}$ & $P^{\prime}$ & $F_{\text {lme }}$ & $P_{\text {lme }}$ \\
\hline Locations & Fixed & 1 & 285.1 & 285 & 3.06 & $>0.05$ & 2.98 & 0.12 & 2.88 & $>0.05$ \\
Infrapopulations & Random & 13 & 93.2 & 93.2 & 1.11 & $>0.05$ & & & & \\
Residuals & Random & 75 & 6303.3 & 84 & & & & & & \\
Total & & 89 & 7800.2 & & & & & & & \\
\hline
\end{tabular}

SS, sum of squares; MS, mean squares; $F_{\mathrm{S}}, F$-statistic; $F^{\prime}$ s, derived $F$-statistic using Satterthwaite's approximation, as devised by Sokal \& Rohlf (1995), for which all criteria were met; $F_{\text {lme }}, F$-value inferred from a linear mixed effect model using REML technique; $P$, probability given $F_{\mathrm{S}} ; P^{\prime}$, probability given derived $F^{\prime} ; P_{1 \mathrm{me}}$, probability given $F_{\text {lme }}$. 
APPENDIX 5. Table of a mixed two-level nested ANOVA of total body mass of male adult nematodes, Anguillicoloides crassus, based on square root-transformed data

\begin{tabular}{llccccccccc}
\hline $\begin{array}{l}\text { Source of } \\
\text { variation }\end{array}$ & $\begin{array}{c}\text { Effect } \\
\text { attribute }\end{array}$ & d.f. & SS & MS & $F_{\mathrm{S}}$ & $P$ & $F^{\prime}$ S & $P^{\prime}$ & $F_{\text {lme }}$ & $P_{\text {lme }}$ \\
\hline Locations & Fixed & 1 & 0.365 & 0.370 & 0.06 & $>0.05$ & 0.06 & 0.82 & 0.13 & $>0.05$ \\
Infrapopulations & Random & 13 & 73.229 & 5.63 & 1.64 & $>0.05$ & & & & \\
$\begin{array}{l}\text { Residuals } \\
\text { Total }\end{array}$ & Random & 53 & 182.39 & 3.44 & & & & & & \\
\hline
\end{tabular}

SS, sum of squares; MS, mean squares; $F_{\mathrm{S}}, F$-statistic; $F^{\prime}$, derived $F$-statistic using Satterthwaite's approximation, as devised by Sokal \& Rohlf (1995), for which all criteria were met; $F_{\text {Ime }}, F$-value inferred from a linear mixed effect model using REML technique; $P$, probability given $F_{S} ; P^{\prime}$, probability given derived $F^{\prime}$ s; $P_{\mathrm{Ime}}$, probability given $F_{\mathrm{Ime}}$.

APPENDIX 6. Table of a mixed two-level nested ANOVA of total lengths of male adult nematodes, Anguillicoloides crassus, based on square root-transformed data

\begin{tabular}{llrrrrrrrrr}
\hline $\begin{array}{l}\text { Source of } \\
\text { variation }\end{array}$ & $\begin{array}{c}\text { Effect } \\
\text { attribute }\end{array}$ & d.f. & SS & MS & $F_{\mathrm{S}}$ & $P$ & $F_{\text {S }}^{\prime}$ & $P^{\prime}$ & $F_{\text {lme }}$ & $P_{\text {lme }}$ \\
\hline Locations & Fixed & 1 & 2.23 & 2.23 & 2.51 & $>0.05$ & 2.24 & 0.17 & 3.16 & $>0.05$ \\
Infrapopulations & Random & 13 & 11.55 & 0.89 & 1.59 & $>0.05$ & & & & \\
Residuals & Random & 53 & 29.60 & 0.56 & & & & & & \\
Total & & 67 & 43.37 & & & & & & & \\
\end{tabular}

SS, sum of squares; MS, mean squares; $F_{\mathrm{S}}, F$-statistic; $F^{\prime}$ s, derived $F$-statistic using Satterthwaite's approximation, as devised by Sokal \& Rohlf (1995), for which all criteria were met; $F_{\text {lme }}, F$-value inferred from a linear mixed effect model using REML technique; $P$, probability given $F_{\mathrm{S}} ; P^{\prime}$, probability given derived $F^{\prime}$ s; $P_{\text {Ime }}$, probability given $F_{\mathrm{Ime}}$. 